corresponding to diffusion path lengths of up to $8 \mathrm{~mm}$. We aimed to determine the microstructural correlates of $S_{\text {cond }}$ and $\mathrm{S}_{\text {acin }}$ in patients with asthma, using ${ }^{3} \mathrm{He}-\mathrm{MRI}$.

Methods Twenty-nine patients with asthma underwent MBW using sulphur hexafluoride as the inert tracer gas, and the parameters $S_{\text {cond }}$ and $S_{\text {acin }}$ were calculated. ${ }^{3} \mathrm{He}$-MRI was performed and the ADC was calculated at both short $(14 \mathrm{~ms})$ and long $(1.5 \mathrm{~s}, 3 \mathrm{~s}$ and $6 \mathrm{~s})$ timescales. ${ }^{3} \mathrm{He}-\mathrm{MRI}$ data was also fitted to a previously reported geometrical model of the acinus (Yablonskiy DA et al, J Appl Physiol. 2009;107(4):1258-65), and estimates of the alveolar duct outer radius (R) and alveolar sleeve width (h) were derived.

Results Correlations between MBW and ${ }^{3} \mathrm{He}-\mathrm{MRI}$ parameters are shown in Table 1. The approximate length scales probed by short and long timescale ADC are also indicated for reference. Significant positive correlations were observed between $S_{\text {acin }}$ and ADC at $14 \mathrm{~ms}, 1.5 \mathrm{~s}$ and $3 \mathrm{~s}$, but not $6 \mathrm{~s}$. In a stepwise linear regression model, $\mathrm{ADC}$ at $1.5 \mathrm{~s}$ was the only significant determinant of $\mathrm{S}_{\text {acin }}$, with a model $\mathrm{R}^{2}$ of 0.334 . $\mathrm{S}_{\text {cond }}$ did not correlate significantly with any of the MRI parameters. Yablonskiy model estimates of alveolar sleeve width and alveolar duct outer radius did not correlate significantly with either $S_{\text {cond }}$ or $S_{\text {acin }}$.

Conclusion $S_{\text {acin }}$ in patients with asthma is associated with an elevated ADC at $1.5 \mathrm{~s}$, corresponding to length scales of the order of $4 \mathrm{~mm}$. This suggests that DCDI in asthma is associated with structural asymmetries at the level of the distal acinar airways and/or collateral ventilation between parallel intra-acinar airways.

\begin{tabular}{|c|c|c|}
\hline & $\mathrm{S}_{\text {cond }}$ & $S_{\text {acin }}$ \\
\hline ADC $14 \mathrm{~ms}(0.5 \mathrm{~mm})$ & .264 & $.470^{*}$ \\
\hline ADC $1.5 \mathrm{~s}(4 \mathrm{~mm})$ & -.080 & $.578^{* \star}$ \\
\hline ADC $3 \mathrm{~s}(5.5 \mathrm{~mm})$ & -.050 & $.471^{*}$ \\
\hline ADC $6 \mathrm{~s}(8 \mathrm{~mm})$ & -.058 & .214 \\
\hline Alveolar duct outer radius (R) & .113 & .273 \\
\hline Alveolar sleeve width (h) & .239 & -.002 \\
\hline
\end{tabular}

\section{S121 ASSESSMENT OF INTERLOBARCOLLATERAL VENTILATION PRIOR TO ENDOBRONCHIAL VALVES TREATMENT FOR SEVERE EMPHYSEMA}

Sk Banerjee, J Babar, A Balan, R Mahadeva; Cambridge COPD Centre, Dept. of Respiratory Medicine and Dept. of Radiology, Cambridge University Hospitals NHS Foundation Trust, Cambridge, UK

\subsection{6/thoraxjnl-2013-204457.128}

Bronchoscopic lung volume reduction (BVLR) with one-way endobronchial valves are employed to reduce hyperinflation to improve symptoms and lung function. The clinical benefits of Zephyr (PulmonX) valves in achieving target lobe volume reduction are most marked in those without collateral ventilation (CV) between ipsilateral non-target and target lobes. The presence of CV can be assessed by visual assessment of fissure integrity on CT scan and by measurement of flow and resistance following balloon catheter occlusion of the target lobe bronchus (Chartis; PulmonX). We have compared these two techniques for assessing collateral ventilation in patients with severe emphysema referred for EBV treatment.
Two respiratory radiologists reviewed the CT images in 19 consecutive patients. Fissure integrity was classified as complete, incomplete minor defect, incomplete major defect. Chartis assessment for CV status was performed on potential target lobes in the same patients, and results compared for the two methods.

There was $57.9 \%(11 / 19), 63.2 \%(12 / 19)$ and $78.9 \%(15 / 19)$ agreement between radiologists on fissure analysis of the right horizontal (RH), right oblique (RO) and left oblique (LO) fissures (Table 1).

In 11 patients with no collateral ventilation on Chartis evaluation to the target lobe; Radiologist 1 reported 9 complete and 2 with incomplete minor defects compared to Radiologist 2; 10 complete and one with incomplete major defect.

In 8 found to be $\mathrm{CV}$ positive by Chartis, radiologist $1 ; 3$ complete, 3 incomplete major and 2 incomplete minor defects, and radiologist 2; 4 complete, 2 incomplete major and 2 incomplete minor defects.

In conclusion, there was inter-observer difference in reporting fissure integrity particularly for right sided fissures, with better agreement for left oblique fissure. However, when experienced chest radiologists scored fissures as complete, there was a high correlation with $\mathrm{CV}$ negative status by Chartis. If radiologists scored fissures as incomplete major only one case was found to be $\mathrm{CV}$ negative whilst $2 \mathrm{CV}$ negative cases were incomplete minor. This data indicates that visual assessment of fissure integrity by experienced respiratory radiologists can be used as a screening tool to determine appropriateness for subsequent Chartis EBV assessment.

\begin{tabular}{|c|c|c|c|}
\hline & Righthoizontal & Right oblique & Let oblique \\
\hline Fissuralagreementh & $11 / 19$ & $12 / 19$ & $15 / 19$ \\
\hline $\begin{array}{l}\text { Radiologist 1 } \\
\text { (complete fssures) }\end{array}$ & 4 & 9 & 13 \\
\hline $\begin{array}{l}\text { Radiologist } 2 \\
\text { (completer fissures) }\end{array}$ & 4 & 13 & 16 \\
\hline $\mathrm{CV}^{\mathrm{x}} \quad$ Rad 1 & 0 & 44 & 719 \\
\hline $\operatorname{Rad} 2$ & 0 & $4 / 4$ & $8 / 9$ \\
\hline
\end{tabular}

Abstract S121 Figure 1.

\section{Pulmonary infection: clinical studies}

\section{S122 STATIN USE IS ASSOCIATED WITH IMPROVED LONG TERM OUTCOMES AFTER COMMUNITY-ACQUIRED PNEUMONIA}

GB Fleming, A Singanayagam, AR Akram, JK Taylor, M Restrepo, AT Hill, JD Chalmers; NHS Lothian, Edinburgh, United Kingdom

\subsection{6/thoraxjnl-2013-204457.129}

Introduction Long term outcomes after community-acquired pneumonia (CAP) are poor, with high rates of readmission, cardiovascular events and mortality. No intervention has previously been shown to alter the excess morbidity and mortality associated with CAP. Statins are effective in preventing cardiovascular disease, but may also have beneficial anti-inflammatory effects. We tested the hypothesis that statin users would have improved long term outcomes following CAP. 